\title{
Comunicación

\section{Diversidad lingüística, comunicación y espacio público}

El presente artículo analiza el problema de la diversidad lingüística en los medios de comunicación en la Unión Europea, tomando en cuenta las relaciones entre las lenguas, territorios e identidades, así como la selección que hacen los medios de comunicación y por lo tanto la visibilidad de algunas lenguas en particular y las relaciones sociales y de poder de los grupos minoritarios dentro de las sociedades democráticas. El autor hace patente la necesidad de tomar en cuenta la reivindicación lingüística más allá del problema meramente cultural, ya que ésta cuestiona al espacio público e implica la redefinición de ciudadanía.

PALABRAS CLAVE: diversidad lingüística, espacio público, nuevas ciudadanías, nuevas identidades, interculturalidad, medios de comunicación.
This paper analyzes the problem of the linguistic diversity in mass media in the European Union, taking into account the relations between languages, territories and identities, as well as the selection that makes mass media and therefore the visibility of some particular languages, social and power relations of the minority groups within the democratic societies. The author makes patent the necessity to take into account the linguistic claims beyond the merely cultural problem, since this one questio$n s$ the public space and implies the redefinition of citizenship.

KEY WORDS: linguistic diversity, public space, new citizenships, new identities, interculturality, mass media.

* Universidad de París 8. Traducción: Celia del Palacio Montiel Correo electrónico: jacques.guyot@univ-paris8.fr. 
Después de una decena de años, las reivindicaciones emanadas de las minorías lingüísticas se traducen en un plan político debido a las demandas de reconocimiento por parte de los Estados y las instancias internacionales. Así, numerosos países europeos han ratificado la Carta Europea de Lenguas regionales o minoritarias.

Estas reivindicaciones han traído particularmente la posibilidad de disponer de más espacio en los medios audiovisuales, y expresan a la vez, la oportunidad de preservar los idiomas en peligro y de darles una mayor audiencia gracias a los recursos de las redes televisivas o satelitales. Esta oscilación entre la preservación de un patrimonio local y la voluntad de disponer de medios oficiales inquieta a aquellos que ven, detrás de la lucha identitaria, el peligro de que se replieguen sobre sí mismos o bien el primer paso hacia la secesión.

Hace ya ocho años que trabajo, solo o con otros colegas europeos, sobre la temática Medios, minorías y democracia. De mi parte, la problemática del modo de existencia de las lenguas minoritarias en los medios se sitúa en la intersección de tres categorías de preguntas: $a$ ) las relaciones entre lenguas, territorios e identidades, $b$ ) la selección de los medios, $c$ ) las posiciones sociopolíticas para las sociedades democráticas.

Si el problema de la presencia de las lenguas minoritarias en los medios audiovisuales es legítimo, la manera de tratarlo pone de manifiesto numerosas interpretaciones ligadas, todas a la vez, a problemas de orden metodológico y teórico; por ejemplo, establecer una definición de una lengua minoritaria, de su territorio; la dificultad de llegar a un estado de la cuestión a partir de protocolos de encuesta basados en criterios diferentes, el estatuto de los investigadores, algunos de los cuales son, antes que nada, militantes, etc., además de las posiciones sociopolíticas. Así, no se pueden reducir las reivindicaciones lingüísticas a un simple fenómeno cultural: éstas interrogan al espacio público e implican la redefinición del concepto de ciudadanía.

Algunas hipótesis de trabajo conducen a esta reflexión. Primero que nada, la idea de que el desarrollo de las tecnologías audiovisuales y las redes hipermediáticas ofrecen indudablemente perspectivas y soluciones a las lenguas de las minorías. Entonces, a pesar de la diversidad y la complejidad de las cuestiones subrayadas, las democracias políticas, 
tanto en la escala nacional como en la de instancias supranacionales, como la comunidad europea, están en posición de tomar en cuenta la pluralidad lingüística. Voy a enunciar algunas de las preguntas relacionadas con las tres categorías previamente mencionadas.

\section{LENGUAS DE LAS MINORÍAS:}

ESTADOS Y LUGARES

¿Cuántas lenguas se hablan en el mundo? La pregunta está lejos de ser simple, sobre todo para aquellas que son practicadas a la sombra de las lenguas oficiales, relegadas a la esfera privada y frecuentemente confinadas a la oralidad. Las definiciones y los inventarios levantan cuestiones sociopolíticas ligadas a la manera de marcar los territorios y de construir las identidades.

\section{Cuestiones terminológicas}

La variedad de expresiones utilizadas manifiesta cada vez la problemática particular de cada proyecto de investigación: lenguas en peligro (con seis grados) (Wurm, 2001); lenguas minoritarias; lenguas menos extendidas; lenguas históricas o regionales (¿cómo tomar en cuenta los nómadas, los inmigrantes y las diásporas?); pequeñas lenguas; lenguas (modimes) (¿el portugués en Europa es más de lo que es en Brasil?). La decisión no es jamás neutra y cada expresión da una visión parcial y particular de la realidad de las prácticas y los territorios lingüísticos, tanto como de las situaciones políticas.

A pesar de todo, la mayor parte de los investigadores se han puesto de acuerdo en un aspecto fundamental que caracteriza las lenguas habladas por las minorías: su estatus oscila entre el acantonamiento en la esfera privada (en la casa, en la familia a través de la trasmisión oral) y la subrepresentación en el espacio público (medios, educación y servicios públicos). Dentro de esta perspectiva, la expresión lenguas minoritarias utilizada por la Oficina Europea para las Lenguas Menos Extendidas (European Bureau for Lesser Used Languages), resulta, primero que nada, ser menos exclusiva: indica una acción conducente a la marginalización o, por lo menos, los obstáculos para que una lengua obtenga un estatus nacional. Desde ahí, la cuestión se plantea 
en términos políticos, en la medida en que aquello que está en juego son las relaciones entre los grupos sociales portadores de un proyecto lingüístico y las autoridades, donde el talento consiste en desviar las políticas lingüísticas. Última ventaja: la expresión no se focaliza en la dimensión territorial y se aplica, tanto a los lenguajes llamados históricos, como a los idiomas nómadas e inmigrantes.

\section{Inventarios y fuentes}

Las fuentes primarias eran poco numerosas, los investigadores han recurrido a los propios inventarios internacionales para documentar sus estudios. La mayor parte de las obras que tratan de los lenguajes del mundo, mencionan una gama comprendida entre 6000 y 6800 . Me gustaría mencionar uno de los catálogos más utilizados, a fin de poner en evidencia uno de los prejuicios metodológicos más característicos, prejuicio que afecta la comprensión del fenómeno: El etnólogo, publicado en 1951 por el Summer Institute of Linguistics (Grimes, 2000), en su $14^{\text {a }}$ edición, fechada en 2000, proporciona la información sobre 6800 lenguas, gracias a una red de corresponsales en 233 países.

Una zona lingüística no corresponde necesariamente a las fronteras de una nación. Puede haber encabalgamientos: el vasco es hablado en Francia y en España, así como el catalán. Una lengua, oficial en un país, puede ser marginalizada en el vecino (el esloveno en Italia y Austria). En la medida en que la lista de lenguajes es establecida sobre la base de lo obtenido en cada país, pueden existir numerosas entradas dobles.

Al final, el número de lenguas debe contabilizarse a la baja (véase cuadro 1). Esto para no hablar de los inventarios que algunas veces integran todas las variedades dialectales de una lengua, y a veces no. Por ejemplo, El etnólogo lista tres variedades de vasco consideradas como lenguas distintas, sin embargo, lista un solo bretón, en el caso en que según el mismo principio, tres variedades pudieron haber sido mencionadas. Esto significa que el criterio de intercomprensión o inteligibilidad mutua que permite discriminar una lengua y sus formas dialectales, es muy suelto. Cuando uno retoma el análisis para Europa e incluye ahí las lenguas de inmigración, la suma final es más menos abundante (véase cuadro 2 ). 


\section{CUADRO 1}

Las lenguas del mundo

Resultados corregidos

Número de lenguas tomadas de 233 países $\quad 6809$

Extracción de entradas duplicadas: $\quad 1703$

Número de lenguas extintas $\quad 334$

Número de lenguas casi extintas $\quad 426$

$\begin{array}{ll}\text { Subtotal 1: } & 4346\end{array}$

Subtotal 2 después de extraer las 112 lenguas

de signos de sordomudos y de dos lenguas

de signos de monjes y de los indios

Lenguas oficiales versus lenguas minoritarias

(Datos compilados por el autor)

193 países utilizan unas 128 lenguas oficiales

11 lenguas son habladas por más de 100 millones de hablantes

chino

hindi

español

inglés

bengalí

árabe

portugués

ruso

japonés

alemán

malasio/ indonesio

$96 \%$ de las lenguas son habladas por $4 \%$ de la población mundial

Más de $50 \%$ no tienen escritura, $25 \%$ desaparecen cada año

Una distribución muy geoestratégica para:

El español, hablado en 21 países por 358 millones de personas

El inglés, hablado en 56 países, por 351 millones de personas

El francés, hablado en 28 países, por 77 millones de personas

El árabe, hablado en 26 países por 200 millones de personas

Fuente: Grimes (2000). 


\section{CUADRO 2}

\section{SITUACIÓN EN LA UNIÓN EUROPEA (15 PAÍSES)}

\begin{tabular}{|c|c|c|c|c|c|c|c|}
\hline & & Prens & & $\mathrm{Ra}$ & dio & Tele & isión \\
\hline Lengua & Estatus & Papel & En línea & Pública & $\begin{array}{l}\text { Privada } \\
\text { o indep. }\end{array}$ & Pública & $\begin{array}{l}\text { Privada } \\
\text { o indep. }\end{array}$ \\
\hline Alemánico & $\mathrm{T}$ & & & $\mathrm{P}$ & & $\mathrm{P}$ & \\
\hline Aragonés & $\mathrm{T}$ & & & & & & \\
\hline Asturiano & $\mathrm{T}$ & $\%$ & & $\mathrm{P}$ & & $\mathrm{P}$ & $\mathrm{P}$ \\
\hline Vasco & $\mathrm{T}$ & & & & & $\mathrm{P}$ & \\
\hline Bretón & $\mathrm{T}$ & $\%$ & & $\mathrm{P}$ & & $\mathrm{P}$ & $\mathrm{P}$ \\
\hline Catalán & $\mathrm{T}$ & & & & & & \\
\hline Cornuallés & $\mathrm{T}$ & & & P & & $\mathrm{P}$ & \\
\hline Corso & $\mathrm{T}$ & $\%$ & & $P$ & & $P$ & \\
\hline Feroano & $\mathrm{T}$ & ND & ND & ND & ND & ND & ND \\
\hline $\begin{array}{l}\text { Franco } \\
\text { provenzal }\end{array}$ & $\mathrm{T}$ & $\mathrm{W}$ & & & $\mathrm{P}$ & & \\
\hline Frisón & $\mathrm{T}$ & M & & $\mathrm{P}$ & & $\mathrm{P}$ & \\
\hline Friulano & $\mathrm{T}$ & $\% \mathrm{~W}$ & & & & & $\mathrm{P}$ \\
\hline $\begin{array}{l}\text { Gaélico } \\
\text { escocés }\end{array}$ & $\mathrm{T}$ & $\%$ & & $P$ & ND & $\mathrm{P}$ & $\mathrm{P}$ \\
\hline Gallego & $\mathrm{T}$ & & & & & & \\
\hline Galés & $\mathrm{T}$ & $\% \mathrm{~W} \mathrm{M}$ & $\begin{array}{l}\text { En } \\
\text { proyecto }\end{array}$ & $\mathrm{P}$ & $\mathrm{P}$ & & $\mathrm{P}$ \\
\hline Inuktikut & $\mathrm{T}$ & ND & ND & $\mathrm{P}$ & ND & ND & ND \\
\hline Ladino & $\mathrm{T}$ & $\% \mathrm{~W}$ & & $\mathrm{P}$ & & $\mathrm{P}$ & \\
\hline Occitano & $\mathrm{T}$ & $\mathrm{W}$ & & $\mathrm{P}$ & & $\mathrm{P}$ & \\
\hline $\begin{array}{l}\text { Lenguas de } \\
\text { Oíl }\end{array}$ & $\mathrm{T}$ & & & & $\mathrm{P}$ & & \\
\hline Póntico & $\mathrm{T}$ & ND & ND & ND & ND & ND & ND \\
\hline Samo & $\mathrm{T}$ & $\mathrm{W}$ & & $\mathrm{P}$ & $\mathrm{P}$ & $\mathrm{P}$ & $\mathrm{W}$ \\
\hline Sardo & $\mathrm{T}$ & ND & ND & ND & ND & ND & ND \\
\hline Sajón & $\mathrm{T}$ & ND & ND & $\mathrm{ND}$ & ND & ND & ND \\
\hline Escocés & $\mathrm{T}$ & & & & & & \\
\hline Siciliano & $\mathrm{T}$ & ND & ND & ND & ND & ND & ND \\
\hline Silesio & $\mathrm{T}$ & ND & ND & ND & ND & ND & ND \\
\hline Suavo & $\mathrm{T}$ & W & & $\mathrm{P}$ & & $\mathrm{P}$ & \\
\hline Árabe & I & $\begin{array}{l}\text { Uso de } \\
\text { medios del } \\
\text { país de origer }\end{array}$ & igual & igual & $\mathrm{P}$ & igual & igual \\
\hline
\end{tabular}




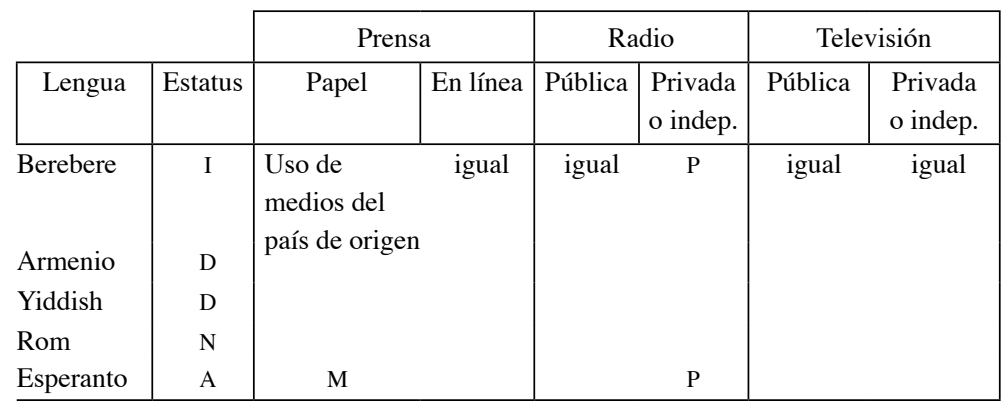

33 lenguas: 27 territorializadas, 2 habladas por inmigrantes, 3 por diásporas y nómadas, 1 artificial.

Notas:

T: Territorializada

I: Inmigrante

D: Diáspora

$\mathrm{N}$ : Nómada

A: Artificial

\%: Artículos cortos ocasionales en los periódicos

W: Semanarios

M: Mensuales

P: Programas regulares

ND: No hay datos

Para contenidos en lenguas minoritarias

- El irlandés es considerado como lengua en peligro

- No se incluyeron las lenguas habladas por los indios y pakistanís en Gran Bretaña (gujarati, hindi, panjabi, pashtou)

En uno de sus libros, Bourdieu remarcó hasta qué punto

el llamarle «occitano» a la lengua que hablan los que llamamos «occitanos» porque hablan esa lengua (la cual ninguna persona habla propiamente hablando, ya que no es sino la suma de varias lenguas diferentes) y de nombrar «Occitania» a la región (en el sentido de espacio físico) donde esta lengua se habla, no es una ficción sin efecto (1982:140). 
Una lengua es un territorio imaginado: el discurso regionalista es típicamente un acto preformativo por sus efectos sociales y políticos. Naturalmente su eficacia es «directamente proporcional a la autoridad que la enuncia» (idem).

Los actos preformativos son presentados en la representación de las identidades y territorios lingüísticos. Esto puede concretamente conducir a sobreestimar el número de locutores (hablantes) y la realidad de sus prácticas lingüísticas. ${ }^{1}$ Esto puede llegar al extremo de negar que la lengua no corresponde todo el tiempo al territorio que lleva su nombre. Este es el caso de Bretaña, cuya extensión geográfica actual es mucho más reducida que el ducado histórico, pero mucho más importante que la zona bretona (bretonnante). Esto tiene naturalmente una incidencia sobre las políticas de difusión audiovisual.

Globalmente, los métodos y herramientas más generales deben ser empleados de manera particular a fin de utilizar las tipologías lingüísticas, recruzando diferentes criterios (estatus sociopolítico, relación con los territorios, procesos migratorios, vitalidad lingüística y demográfica, sociología de los hablantes, etc.). Naturalmente, las encuestas deben ser conducidas dentro de las lenguas minoritarias y evaluar el nivel de competencia, así como el grado de alfabetización. Incluso, si el investigador es un defensor de las minorías, lo cual es frecuentemente el caso, el interés científico que emana de una pasión personal, debe apartarse de sus prejuicios ideológicos, cuestionar sus prenociones y aplicar sistemáticamente la «duda metodológica» (Durkheim, 1937).

\section{LOS MEDIOS}

La expresión mediática de las lenguas minoritarias constituye por mucho, una reivindicación legítima y una cierta ventaja, incluso si no pudiera ser una condición suficiente para poder revitalizar la lengua.

1 Numerosas encuestas sobre la práctica de las lenguas minoritarias son tomadas por la lengua oficial. Lo que se prueba no es la competencia lingüística real, sino una relación superficial con la lengua minoritaria. Otra vez, es la magia del discurso preformativo que se opera: si yo digo que hablo Bretón (en francés), entonces yo soy Bretón. 
Los medios ofrecen una gama de formas de comunicación que pueden ayudar a una lengua a conquistar una audiencia más grande y a salir de la marginalidad. El acceso a los medios supone una reflexión en términos de expectativas y de selección. Sobre el primer punto, lo que los defensores de las lenguas minoritarias esperan de los medios es, frecuentemente, impresionante.

\section{Los efectos de los medios}

Si menciono este punto en particular es porque existe todavía una creencia muy fuerte sobre la omnipotencia de los medios. Este mito es paradójicamente compartido por los individuos y los grupos que, por un lado desconfían de los medios nacionales e internacionales a los cuales acusan de propagar la ideología de mercado y los contenidos estandarizados, y por otro, piensan que ya que los medios suben el peldaño local, sus efectos están embellecidos por todas las virtudes.

Esta actitud va en contra de todos los estudios sobre la influencia social de los medios, los primeros trabajos anglosajones de los años cuarenta (Lazarfeld y Katz, 1955) sobre estudios culturales, pasando por las encuestas sobre prácticas televisivas de los niños (Schramm, Lyle y Parker, 1961). En resumen, no hay evidencia alguna de un lugar de causalidad lineal entre los mensajes de los medios y el comportamiento de los individuos. El hombre es imprevisible, último alarde hacia la mira propagandística en una época donde jamás las técnicas de manipulación política o comercial habían sido tan deplorables.

Sin embargo, el sentido común de un medio forzosamente resiste los diversos avances científicos. Incluso si los resultados de la investigación no han alcanzado al gran público o si los usuarios de los medios asocian dentro de un movimiento de convivencia a los sociólogos y a los estudiosos y profesionales de los medios. El mito se ha cristalizado en la televisión, el medio por excelencia. Ya se trate de redes televisivas internacionales, cadenas privadas comerciales o de la televisión bajo el monopolio del Estado, una gran mayoría está convencida de que la televisión es una mala influencia.

Al mismo tiempo, los medios locales, regionales o comunitarios, son considerados bajo un ángulo totalmente diferente: como lo demuestran los sociólogos y los etnólogos, este interés por lo local puede ser 
interpretado como una reacción singular a la desterritorialización de los espacios sociales y culturales tradicionales, engendrado por la internacionalización de los sistemas de comunicación y de las economías (Mattelart, 1992). Esta reacción privilegia a las culturas populares o regionales sobre la producción mediática internacional, ya que la facilidad de uso de un lugar social encarnado contrapuesto al anonimato de las redes inmateriales -sin renegar, sin embargo- de las posibilidades abiertas por las tecnologías de la información y la comunicación (Guyot, 2002).

Sorprendentemente, las minorías rara vez han recurrido a la vasta gama de los medios. Tan celebrada fue la prensa por Gabriel Tardé en su tiempo, que le asignó un rol importante en la construcción de la opinión pública (Tardé, 1989). En muchas zonas rurales donde los libros no circulan bien, las generaciones de niños y de adultos han aprendido a leer gracias los periódicos. A otro nivel, el cine ha podido sobreponerse a la diversidad cultural y permite a los miembros de una minoría tomar conciencia de su singularidad. ${ }^{2}$ Por otro lado, la radio constituye un medio de comunicación muy flexible, tanto desde el punto de vista técnico, así como económico. Aunque la radio está asociada a la oralidad, ha sido utilizada igualmente con éxito en las campañas de alfabetización o de aprendizaje de lenguas. Un panorama del uso de las lenguas minoritarias en los medios tradicionales, muestra que en el mejor de los casos, esta presencia es marginal en la vida cotidiana, en la radio y en la televisión. Si se trata de preservar o favorecer su lengua, las minorías deben luchar por poner en su lugar a los medios independientes. Estos son confrontados por problemas económicos, principalmente porque la escala de los mercados implica tocar públicos importantes. Un ejemplo significativo: el periódico gratuito Veinte minutos, recoge 100000 euros por día en un tiraje de 450000 ejemplares y vende cada página de publicidad en 12000 euros.

Con la llegada de los hipermedia, los medios de comunicación tradicionales como el periódico, la radio y hasta la televisión, ven su fuerza disminuida: la posibilidad de mezclar los contenidos de los

2 Ver, por ejemplo, Atarnajuat. The fast runner, película de 1999 sobre los inuits, producida por Isuma Productions, Inc. 
medios, facilidad de uso, abolición de las barreras espacio temporales y sobre todo, costos de funcionamiento reducidos.

La mayor parte de las minorías no sacan provecho de sus posibilidades. Es verdad que algunos grupos culturales o asociaciones lingüísticas llevan a cabo de vez en cuando algunos experimentos, pero, en conjunto, no existe estrategia de hipermedios. Así, casi no hay periódicos en línea (véase cuadro 2). Por supuesto, más de la mitad de las lenguas del mundo no dispone de escritura. Pero, si tomamos el caso de Europa, todos los idiomas podrían lanzar un periódico cotidiano en la internet. En realidad, sólo el vasco, el catalán, el gallego y el galés tienen prensa cotidiana en línea. Por lo tanto, nada impide que se pase directamente a la edición electrónica. No es necesaria una inversión estructural muy pesada, no es necesario lidiar con imprentas o una compañía de distribución, no hay que comprar papel. Estas categorías presupuestales van de 40 a $65 \%$ del precio de menudeo.

La otra ventaja es que la internet está adaptada para tocar a los pequeños grupos, particularmente en el caso de las minorías desterritorializadas. De hecho, el concepto de medios masivos es particularmente apropiado para describir un medio cuya lógica reticular privilegia las relaciones interactivas y convivenciales. En resumen, los nuevos medios pueden responder a las necesidades de los públicos fragmentados.

Al final, pero no por ello menos importante, está la función de archivo, lo que significa que vía internet el lector puede consultar viejos números, lo cual puede constituir un punto fuerte en la medida en que las lenguas minoritarias disponen frecuentemente de poco material escrito, particularmente para aquellos que quieren aprenderla.

David Crystal (2000) tiene razón cuando, entre los seis temas claves que evoca para favorecer la revitalización lingüística, menciona el acceso a nuevas tecnologías. Eso que podría parecer una nueva utopía comunicacional, a la manera de los medios comunitarios de los años setenta, implica esta vez a los medios relativamente razonables sobre el plan económico.

En resumen, no hay que sobreestimar el poder de los medios ni idealizarlos, pues repetidamente han sido utilizados para manipular las conciencias (Ellul, 1990; Ramonet, 2000) o para servir a los 
tecnólogos (Friedmann, 1979). Los medios contienen tanto promesas de emancipación como amenaces para la libertad y el porvenir. En los límites del cuadro, los aparatos de comunicación deben beneficiarse de las lenguas. En un nivel la Tecnología de Información y Comunicaciones (TIC), de la cual se sabe en algún punto que aumenta las desigualdades socioculturales, constituyendo un déficit suplementario para las minorías que no quieren desaparecer en los márgenes de la sociedad de la información: el acceso a las nuevas tecnologías debe ser estimulado y facilitado por las instituciones educativas y las asociaciones culturales que trabajan por la diversidad lingüística.

\section{Lenguas minoritarias en el espacio público}

En los años 1990, los trabajos sobre multiculturalismo encontraron un eco favorable en el medio académico, gracias a las obras de Charles Taylor (1994) y Hill Kymlicka (2001), entre otros, al mismo tiempo que en el mundo político, principalmente a través de las políticas de discriminación positiva o de los debates sobre lo políticamente correcto. Estas problemáticas norteamericanas, frecuentemente presentadas como una apología a la diferenciación identitaria, facilitan nada menos que los debates que aquí y allá, a través del mundo, plantean la pregunta de la legitimidad de las reivindicaciones culturales en el espacio público.

\section{A propósito del multiculturalismo}

La noción en sí misma es polisémica y polémica. «Este no es ni un concepto ni una teoría ni un movimiento social ni político, aunque pretende ser todo eso a la vez» (Bourdieu y Wacquant, 2000). Más allá del éxito del término, el interés por el multiculturalismo es considerado frecuentemente como el resultado de la crisis de la modernidad cuyos efectos han sido acentuados por los fenómenos de la internacionalización de los sistemas de comunicación. ¿De qué se trata exactamente? El retorno de la subjetividad, la revancha de las culturas, o para decirlo de otro modo, la aparición de oposiciones binarias: global-local, universalismo-comunitarismo, racionalidad-subjetividad.

Hill Kymlicka piensa que las reivindicaciones de las minorías para obtener los derechos administrativos y políticos deben ser satisfechas por las autoridades políticas, en particular en los casos de las minorías 
nacionales (los indios americanos, los bretones o los catalanes). La teoría liberal de los derechos de las minorías (Kymlicka, 2001), así como la política del reconocimiento defendida por Taylor (1994) han sido frecuentemente criticadas, ya que postulan que lo que prevalece es la autonomía de los individuos considerados como seres racionales y responsables. En sustancia, en el seno de los grupos sociales, sus acciones son preeminentes y toca al sistema político adaptarse a sus demandas que emanan de la sociedad civil. Esta concepción privilegia a las minorías suficientemente numerosas en un lugar dado para organizarse y hacerse oír por las autoridades: es el caso de los grupos lingüísticos constituidos por los habitantes históricos de una región. En este caso, una minoría debe localmente ser una mayoría para poder aplicar sus derechos lingüísticos (Kymlicka, 2001:164). Esto excluye de facto a comunidades lingüísticas invisibles, de las cuales hablaremos más adelante: los nómadas, las diásporas o emigrantes.

A otro nivel, el multiculturalismo está más preocupado por teorizar el lenguaje políticamente correcto, que verdaderamente por la cuestión del multilingüismo.

Finalmente, el multiculturalismo no llega siempre a tomar en cuenta la jerarquía sociopolítica de las apuestas culturales. Por ejemplo, ¿puede uno definir la tradición centralizadora francesa mencionando por un lado el asunto del velo islámico y por el otro, la autonomía territorial de Córcega, cuestiones que en cualquier otro país, según Kylimcka, hubieran sido arregladas desde hace mucho tiempo?, ¿puede uno, sobre todo, meter en el mismo plano, eso que, por una parte es presentado como un inofensivo signo cultural que merece ser reconocido dentro de lo que él llama multiculturalismo de inmigración y por otro lado, el futuro de una isla que obtendrá, de un modo u otro una forma de autonomía?3 De hecho, el multiculturalismo es generalmente muy laxo para tratar las consecuencias políticas de ciertas especificidades culturales (o al menos consideradas como tales).

3 En el prólogo de la edición francesa de su libro, Kymlicka menciona estos dos ejemplos para ilustrar la oposición del Estado francés a las reivindicaciones culturales. El caso de Córcega se inscribe en lo que él nombra federalismo multinacional. 
En suma, el multiculturalismo profesa una cierta negación de la política, pero vincula igualmente una visión muy restrictiva y esencialista de la construcción identitaria. Amin Maalouf, novelista franco-libanés, muestra bien cómo su identidad construida en la intersección de tradiciones diferentes y de múltiples pertenencias, forma (relève) un esquema más intercultural y sobre todo, toma todo su sentido por la adhesión a referencias comunes. Esta actitud ciudadana representa, para el politólogo Fred Constant «una primera regla de saber vivir en la pluralidad» (2000).

\section{Un acercamiento europeo de la pluralidad cultural y lingüística} La noción de multiculturalismo está fuertemente marcada por el contexto norteamericano, como lo ponen de manifiesto Bourdieu y Wacquant:

Es un término que, en Europa ha sido sobre todo utilizado para designar el pluralismo en la esfera cívica, mientras que en Estados Unidos nos reenvía a aquellas persistencias de la exclusión de los negros y a la crisis de la mitología nacional del «sueño americano» (1998).

Esta noción no corresponderá entonces a las realidades europeas o a las cuestiones ligadas a la pluralidad cultural y lingüística que han sido siempre parte del debate público. Así, incluso en Francia, país frecuentemente estigmatizado por los militantes de las minorías regionales, las disposiciones legales integradas en las misiones de servicio público de las sociedades audiovisuales existen a fin de asegurar una presencia de las lenguas históricas de las regiones.

La pregunta que se plantea es entonces imaginar cómo la diversidad lingüística tomada, puede ser más ampliamente y más sistemáticamente tomada en cuenta en la vida pública como en los medios. Dentro del contrato social que son las constituciones por las que se rigen las naciones se puede encontrar la selección más variada para garantizar la libertad individual y colectiva y la igualdad de los ciudadanos. Algunos países mencionan las cuestiones lingüísticas (Francia, de manera exclusiva, España con una visión más extensiva y Gran Bretaña), mientras que otros no (Estados Unidos). Cada constitución descansa sobre un cierto número de principios 
estableciendo qué cae dentro de la vida privada y qué corresponde al espacio público, es decir, qué merece ser publicitado. Habermas $(1986,1989)$ ha analizado el proceso de perversión del principio de la publicidad, así como la refeudalización del espacio público. La filosofía de las luces asoció el ejercicio de la razón y el ejercicio de la subjetividad y no es sino hasta hace pocos años, que los asuntos culturales han formado parte del debate público. Estas cuestiones no son de poca importancia, sin duda menos culturales de lo que quieren mostrar. Esto significa que el espacio público democrático debe ser reformulado y Habermas está consciente de que la diversidad cultural debe ser tomada seriamente en cuenta. Pero, a fin de evitar una simple acumulación de guetos o comunidades que sean reconocidas a través de derechos específicos, el piensa que la noción de tolerancia puede constituir el modelo para teorizar las sociedades multiculturales. Esta noción, heredada de la época de las guerras de religión, es muy interesante porque supone un nuevo contrato social entre diferentes grupos capaces de compartir una visión común del mundo.

Desde una perspectiva más sociológica, Michel Wieviorka aborda el problema desde el ángulo de la etnicidad. Refuta la idea de que se podría reducir el debate a la oposición entre tradición y modernidad, comunidad y ciudadanía. Pone de manifiesto también que en Francia la asimilación de los inmigrantes ha sido considerablemente facilitada por la pertenencia a la comunidad de origen que ha jugado un papel vital al absorber el golpe causado por el desraizamiento y el exilio, permitiendo así un acceso gradual a la ciudadanía francesa. Dentro de este contexto, la lengua materna constituía una gran parte de ese lugar. Wieviorka propone una definición sociológica de la etnicidad a la cual él considera como un espacio organizado alrededor de tres polos indisociables y complementarios: $a$ ) individualismo y los valores universales (herencia del siglo de las Luces); b) la subjetividad (la identidad cultural), y $c$ ) el comunitarismo (las redes y solidaridades comunitarias) (1993:125136). Este modelo puede ser trasportado a muchos grupos lingüísticos que han tenido que sufrir la modernidad y sus consecuencias en la normalización de la vida sociocultural. Este modelo resume también las tensiones y dificultades que el actor social experimenta mientras navega en el seno de este triángulo de la etnicidad. 
En toda hipótesis, algunos de estos acercamientos teóricos pueden proveer de modelos, con la reserva de adaptarlos a diferentes situaciones, respetando a la vez la diversidad cultural y la adhesión a un contrato sociopolítico común. Es en este panorama que las cuestiones lingüísticas merecen ser reconocidas y promovidas. Incluso si todavía existen numerosas tensiones y oposiciones, el debate ha llegado a la madurez. Los progresos revelan la cualidad de la reflexión pública y el equilibrio de fuerzas.

\section{Minorías, exclusión y democracia}

La existencia de una lengua está ligada a la situación geopolítica y económica (Calvet, 2002). Nacional y regionalmente, los mismos factores juegan un papel importante, particularmente en lo que toca a la existencia de las lenguas minoritarias.

En efecto, las regiones prósperas como Cataluña, han estado en una posición favorable para promover su lengua. La implantación territorial constituye también un triunfo que ha conferido visibilidad y por tanto, una legitimidad que facilita el reconocimiento oficial. Para Michel de Certau (1980), el territorio -con todas las instancias representativas y las instituciones culturales que de ellas se desprenden- es un elemento esencial para desarrollar una estrategia: las minorías territorializadas pueden hablar a partir de un propio, es decir, de un lugar capaz de resistir el desgaste del tiempo. Es la articulación de una estrategia y de una táctica (la utilización del tiempo) lo que permite poner en su lugar una política.

Desgraciadamente, las lenguas de los nómadas y de los inmigrantes no pueden beneficiar este anclaje a un lugar. Es más, estos grupos sociales son los primeros en sufrir ostracismo y racismo. Además de todo eso, son las víctimas de la exclusión socioeconómica y política. Esto significa que no sirve de nada defender una lengua sin luchar con todas las formas de exclusión. Ahí también, la cuestión lingüística es eminentemente política.

En Europa, esto tiene que ver con dos tipos de minorías no territorializadas. Los gitanos, llegados de la India a principios del siglo $\mathrm{XV}$, son una minoría particularmente vulnerable. En muchos países, estos grupos son confrontados a la violencia, el odio y la relegación hacia los márgenes de los espacios físicos y simbólicos. Ellos acumulan 
todos los signos de marginación: desempleo elevado, analfabetismo y delincuencia. El romani y sus formas dialectales rara vez son enseñados, para no hablar de su ausencia en los medios de comunicación. Todo proyecto consagrado a la protección de los gitanos debe incluir la dimensión política y social.

En lo que concierne a los inmigrantes, como los magrebíes en Francia, son también invisibles. En un contexto general de crisis económica y de conflictos sociopolíticos, ellos cristalizan el resentimiento de la población que los recibe (discriminación racial, violencia de la extrema derecha). La mayor parte de ellos practica su lengua materna en la casa. Ellos hacen uso de los medios audiovisuales (programas de televisión y videocasetes). Una parte del material de video ha sido distribuido en las afueras por los grupos radicales islámicos. Las emisiones visuales provienen de redes satelitales controladas por países como Arabia Saudita. La paradoja es que un cúmulo de países receptores temen mucho los efectos negativos de esta propaganda islámica, pero no hacen nada para ofrecer alternativas sobre el propio sistema mediático. Una mayoría de las redes satelitales europeas no propone un canal específico a los inmigrantes, con una información plural de emisiones culturales o de programas de alfabetización. Indudablemente, las democracias europeas han fracasado en reconocer la importancia de muchas de estas lenguas de inmigrantes en su espacio público mediático.

\section{La importancia de las instancias supranacionales: el caso de Europa}

De cara a sus contradicciones históricas, muchos países ponen freno a las reivindicaciones que emanan de las minorías lingüísticas. Si España o Gran Bretaña han acordado formas de autonomía o de descentralización a sus regiones, la mayoría, no solamente Francia, se atienen a una organización de base de la expresión mediática de las lenguas minoritarias. 4

4 En Europa, la mayor parte de las instituciones audiovisuales públicas -radio y televisión- reservan segmentos y horarios específicos para las lenguas minoritarias en las barras programáticas regionales. Por ello, la cuestión lingüística figura generalmente como una de las numerosas obligaciones del servicio público de las estaciones y las cadenas. Esto explica el volumen reducido de los programas consagrados a esas lenguas (Guyot, 2002). 
Es por ello que todos estos países pertenecen a identidades políticas y económicas más vastas. Este es el caso en Europa desde la creación del Consejo Europeo en 1949. El consejo compuesto por 44 estados miembros, ha desempeñado una política muy activa en el territorio de los derechos humanos. Esto concierne también a los derechos de las minorías. Comparado con los otros continentes, Europa tiene menos lenguas, pero en conjunto, éstas están más protegidas gracias a la existencia de un marco legal. En este contexto, dos tratados merecen atención particular: la Carta Europea de Lenguas regionales y minoritarias y la Convención Marco para la protección de las minorías nacionales.

La Carta, adoptada por el consejo el 25 de junio de 1992, está basada sobre el principio de que los derechos lingüísticos forman parte de las libertades fundamentales. Ella expresa igualmente la conciencia de que las lenguas europeas son una herencia preciosa que contribuye a nuestro bien común y nuestras tradiciones. Su ratificación por cinco Estados en 1975 desembocó en su aplicación efectiva en 1988. Cuando un Estado decide ratificar la carta, puede escoger las lenguas que desee proteger y se compromete a «aplicar un mínimo de 35 párrafos o (alinéas)». $5 \mathrm{La}$ aplicación de la Carta da como resultado la responsabilidad de cada uno de los miembros signatarios. Hoy en día, 27 países la han firmado y 14 de ellos la han ratificado.

Contrariamente a lo que frecuentemente se afirma, cuando un país decide no ratificar la Carta (como Francia), esto no significa necesariamente que el país en cuestión rehúsa la enseñanza o la presencia de las lenguas minoritarias en los medios. Generalmente, esto indica que ciertos artículos de la Carta están en contradicción con la constitución de un país miembro. Es por ello que los cambios constitucionales deben ser hechos por las asambleas ad hoc: esto exige un debate público interno y, como ya lo he dicho antes, las proposiciones se discuten actualmente, a pesar de las tensiones y las resistencias. Otro punto que debe ser señalado, es que la Carta no toma en cuenta las lenguas de los inmigrantes.

La ventaja de la Carta es que muchos Estados la utilizan para definir su política lingüística. Esto es particularmente importante por los 10

5 Véase el texto completo en http://conventions.coe.int/Treaty 
países candidatos a entrar en la Unión Europea. Entre otras cosas, el tratado incluye un cierto número de cláusulas que contienen, para los candidatos, criterios de eligibilidad.

En cuanto a la Convención Marco para la protección de las minorías nacionales, ésta se firmó el 1 de febrero de 1995. Ratificada por 12 países, tuvo efecto en febrero de 1998. Digamos que el Marco es un poco débil e impreciso. Es un contrato que ofrece una protección mínimamente aceptable a las minorías. Se le puede considerar como una primera etapa hacia el reconocimiento de criterios lingüísticos contenidos en la Carta.

En estos dos casos, las instituciones europeas procuran un arsenal jurídico que dé sustancia a las cuestionen linguiísticas: el tratado y la convención establecen un espacio institucional junto con los Estados miembros y sobre todo, los dos textos postulan que las cuestiones lingüísticas deben ser discutidas en el espacio público democrático.

\section{ALGUNAS OBSERVACIONES \\ A GUISA DE CONCLUSIÓN}

Quisiera concluir con documentos reproducidos de dos páginas electrónicas. Una de ellas integra dos instituciones 6 afiliadas al Summer Institute of Linguistics, una ONG cristiana que ya ha sido mencionada más arriba. La presentación dice:

Existen todavía más de 300 lenguas donde hace falta el vocabulario de Dios. Una lengua no puede estar completa sin la palabra de Dios. En muchos casos entre las culturas del mundo, las palabras como redención, perdón y amor no pueden conseguir su plena expresión, en tanto que el amor de Dios no haya sido introducido (The Seed Company).

Más de 300 millones de personas a través del mundo todavía necesitan la palabra de Dios en su propio idioma. Al ritmo actual de las traducciones, todavía habría que esperar 100 o 150 años. ¡Es demasiado tiempo! [...] si una

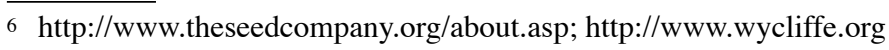


misión internacional de traducción de la Biblia nos interesa, nuestro deseo es ayudarle a encontrar una vía para que se incorpore (Wycliffe).

La segunda página se trata del sitio US English que proporciona una base datos sobre las lenguas minoritarias. Se trata también de gente muy motivada:

En numerosos países a través del mundo, la fundación US English ha realizado investigaciones sobre los aspectos legales de las lenguas oficiales o minoritarias. Creemos que es absolutamente vital que nuestros ciudadanos, nuestros gobernantes y educadores tengan conciencia de los problemas lingüísticos que envenenan a nuestras naciones alrededor del globo. ${ }^{7}$

La fundación US English hace un trabajo intenso de lobby para introducir un nuevo artículo en la Constitución Norteamericana: el inglés será la lengua oficial de Estados Unidos. En efecto, hasta el día de hoy, no existe ninguna mención a esto en los textos. Mientras que muchos países en el mundo (Bolivia o la Unión Europea) procuran responder a las reivindicaciones lingüísticas, Estados Unidos quieren oficializar el inglés a fin de erradicar el multilingüísmo y sobre todo, enfrentar el reconocimiento del español.

Estas citas muestran que aquellos que toman a las lenguas minoritarias como objetos de estudio, no están necesariamente interesados en la defensa de la diversidad cultural en el nombre de los derechos humanos o lingüísticos. De ahí la necesidad de disponer de centros de investigación totalmente independientes de grupos políticos o religiosos. La Unión Europea financia ya a redes como la Oficina Europea de Lenguas Menos Utilizadas (BELMR) y también el observatorio Mercator. Todavía queda integrar a estas redes los acercamientos pluridisciplinarios, interrogar a las lenguas minoritarias con métodos rigurosos y la distancia crítica y el reposicionamiento en su contexto sociopolítico. Una iniciativa de ese tipo ha tenido lugar en el primer simposio de Mercator Media Forum, en abril de 2002: alrededor de la figura de un colega de la universidad de Stirling (Escocia), una red interuniversitaria está constituyéndose; el objetivo

7 http://us-english.org/fundation/countries.asp 
de Minority Language media network (Red de medios de lenguas minoritarias) es estudiar las consecuencias sociopolíticas, culturales y tecnológica de las expresiones mediáticas de las lenguas minoritarias.

\section{Bibliografía}

Bourdieu, Pierre (1982) Ce que parler veut dire. L'économie des échanges linguistiques. París: Fayard.

- y Louis Wacquant (1998) «Sur les ruses de la raison imperialiste». En Actes de la recherche en sciences sociales, 122. Marzo.

- (2000) «La vulgate planetaire». En Le Monde Diplomatique. Abril. CALVET, Louis Jacques (2002) Le marché aux langues: les effets linguistiques de la mondialisation. París: Plon.

Certeau, Michel de (1980) L'invention du quotidien. Arts de faire 1. París: UGE 10/18.

Constant, F. (2000) Le multiculturalismo. París: Flammarion.

CRYSTAL, David (2000) Language death. Cambridge: Cambridge University Press.

DURKHEIM, Émile (1937) Les règles de la méthode sociologique. París:

Presses Universitaires de France.

Ellul, J. (1990) La technique ou l'enjeu du siècle. París: Económica.

FRIEDMANN, G. (1979) Ces merveilleux instruments: essai sur les communications de masse. París: Denoël/Gonthier.

GRIMES, Barbara F. (2000) Ethnologue: languages of the world. Vol. 1. Dallas, Texas: SIL International.

- (2000a) Ethnologue: maps and indexes. Vol. 2. Dallas, Texas: SIL International.

GUYOT, Jacques. (2001) «Une châine bretonne privée à l'ère du numérique. Quelques considérations socio-politiques sur la création de T.V. Breizh». En Mercator Media Forum, 5. Cardiff: University of Wales Press.

- (2002) «Intercultural Challenge for French Television». En N. Jankowski y O. Prehn Community media in the information age. Perspectives and prospects. Cresskill, Nueva Jersey: Hampton Press, Inc.

- Ledo M. y R. Michon (2000) «Production télévisée et identité culturelle en Bretagne, Galice et Pays de Galles- Produerezh skinwel 
hag identelezh sevenadurel e Breizh, Galiza ha Kembre». En Klask,

6. Rennes: Presses Universitaires de Rennes.

HABERMAS, Jürgen (1984) L'espace publique. París: Payot.

- (1989) The structural transformation of the public sphere. Cambridge:

Mass. MIT Press. Hay version en español: Historia y crítica de la opinion pública. Gustavo Gili, ed. Barcelona, 1994.

KYMLICKA, W. (2001) La citoyenneté multiculturelle. Une théorie libérale du droit des minorités. París: La découverte.

LAZARFELD, Paul y Eliu Katz (1995) Personal influence: the part placed by people in the flow of mass communications. New Cork: Free Press.

Mattelart, Armand (1992) La communication monde. Histoire des idées et des stratégies. París: La Découverte.

Morley, D. y K. Robins (1996) Spaces of identity. Global media, electronic landscapes and cultural boundaries. Londres: Routledge.

RAMONET, Ignacio (2000) Propagandes silencieuses. Masses, télévision, cinéma. París: Galilée.

SCHRAMM, Wilbur; Lyle, J. y E.B. Parker (1961) Television in the lives of our children. Stanford: Stanford University Press.

TARDÉ, Gabriel (1989) L'opinion et la foule. París: PUF.

TAYLOR, Charles (1994) Multiculturalisme. Différence et democratie.

París: Flammarion.

WiEviorka, M. (1993) La démocratie à l'èpreuve. Nationalisme, populisme, ethnicité. París: La Découverte.

- (ed.) (1996) Une société fragmentée? Le multiculturalisme en débat. París: La Découverte.

WuRM, S.A. (2001) Atlas of the world's languages in danger of disappearing. París: UNESCO.

Fecha de recepción: 10/01/05. Aceptación: 18/07/2005. 